\title{
Influence of Fancy Rope Skipping on Student Corporeity under Driven Teaching Model
}

\author{
Zou Yebing \\ Jiangxi University of Traditional Chinese Medicine, Physical Education Department, Nanchang \\ Jiangxi, China, 330004
}

Keywords: driven teaching; fancy rope skipping; student corporeity

Abstract: To better study the influence of fancy rope skipping on student corporeity and promote student's healthy growth, the follow-up survey of the influence of fancy rope skipping on student corporeity is conducted combined with driven teaching model. The students' corporeity situation of a certain junior high school are grouped, tested and compared to obtain the data such as students' average height, weight and lung's capacity, then the students' corporeity changes are also grouped and tested. The test results showed that the fancy rope skipping can effectively improve the students' corporeity, develop students' endurance and will. Therefore, it's better to add the fancy rope skipping to daily teaching activities to promote the mental and physical healthy development of students.

\section{Introduction}

As a new type of sports, the fancy skipping rope combines the dynamic and fashion elements of modern sports on the basis of traditional skipping ropes, effectively combining health, fitness, appreciation and popularization characteristics ${ }^{[1]}$. It helps to promote students' physical and mental health, cultivates students' hobbies in daily sports, and fully meets the current students' growing needs. Therefore, it is deeply loved by school teachers, parents and students in the promotion process. Analysis of the current physical characteristics and health status of Chinese students showed that most students are affected by too many classes, lack of daily exercise, and in poor health status. In order to further study and investigate the students' physical health quality, based on the driven teaching mode, the influence of fancy skipping on the physical shape and physical function of students is analyzed, and the relevant factors that restrict the physical fitness of students are deeply analyzed ${ }^{[2]}$. According to the research results, the promotion of the pattern skipping movement is targeted to achieve the goal of enhancing students' physical fitness and promoting students' healthy growth. Through investigation and research, it is confirmed that through the development and utilization of the pattern skipping course, the physical development of adolescents can be effectively promoted.

\section{Research on influence of fancy rope skipping on student corporeity under driven teaching model}

Driven teaching is a teaching method based on the teaching materials, combined with the fun of 
the game to enrich the original teaching connotation, play the guiding role of the game. Teaching through the driving teaching mode can effectively provide students with emotional and practical experience ${ }^{[3]}$. The fancy rope skipping exercise is the most moderately loaded exercise for the healthy growth of students. In order to further improve the students corporeity, in the teaching time of physical education in schools, the research on the influence of fancy rope skipping on students' physical fitness is carried out based on the driving mode.

\subsection{Research objetcs}

Because the students in the middle and upper grades are still in the stage of rapid growth and development, their changes are more obvious [4]. Therefore, taking the first-year students of a junior high school as the research object, selecting the method of sampling selection, randomly selecting a university, randomly selecting 12 class students in the first grade, and conducting health tests. After eliminating 6 students with cardiopulmonary disease and motor function impairment during the test, a total of 180 people were involved in the test. There are 96 male students and 84 female students. Most of the students who are inspected are between 12-13 years old. The average age of the students tested is $12.4 \pm 0.2$ years old. The students were randomly assigned to two groups, each group consisting of 48 males and 42 female students, which were the research group and the control group, and it should be ensured that the age and gender distribution of the two groups were balanced, and the average health status was basically the same [5].

\subsection{Research method}

Using the self-control and two-group comparison test methods, the fancy skipping practice course was added three times a week to the study group students course in the same time and under the same conditions, and the control group was given a general physical education course.

Among them, the experimental group's fancy skipping training includes: single jump, pendulum jump, double fly jump, back jump, crosses jump and other single rope skipping methods, double rope skipping method such as interactive rope pattern, rope technology, and multi-person rope skipping method such as pattern wheel jump position and crossover. The test inspection time was 6 months. The two groups of students practiced three times (an hour each time) a week on Monday, Wednesday and Friday to effectively study the effect of the student group skipping training. And compared with the teaching results of the physical education class of control group which completes the same number and time according to the normal sports, the overall class hours, credit hours and student attendance and teacher level of the two groups of students are guaranteed to be the same [6].

\subsection{Trace and check}

Before and after the follow-up monitoring, the physical health of the two groups of students was tested. The test contents include: height, weight and other morphological index; physical indicators such as sprint, middle and long distance running, and long-distance running; and body-level indicators such as high jump, long jump, pull-ups, sit-ups, and health indicators such as heart rate, blood pressure, and vital capacity [7]. In the process of training and contrast testing, the two groups of personnel are trained and guided by the same batch of professionals, and the professional medical staff measures and records the physical functions of the students, and the physical quality indicators are measured by the physical education teachers. The student's body fat percentage (F\%) and skinfold thickness were calculated with: $(4.652 /$ body density-4.018) $\times 100 \%$. The calculation method of body density is: [(weight/height) average $\times 100 \%] \pm$ standard deviation, using modern statistical software to test student data, if the test value is greater than 0.05 , it is a significant difference 
standard of institutional data. The physical examination parameters of the students before the intervention are as follows:

Table 1. Physical examination parameters of the students before the intervention

\begin{tabular}{|c|c|c|c|c|}
\hline \multirow{2}{*}{ Index parameters } & \multicolumn{2}{|c|}{ Average value of the control group } & \multicolumn{2}{|c|}{ Study group average } \\
\hline & Female student & Male student & Female student & Male student \\
\hline Height $(m)$ & $1.60 \pm 0.3$ & $1.73 \pm 0.4$ & $1.61 \pm 0.2$ & $1.72 \pm 0.3$ \\
\hline Weight $(k g)$ & $40-50$ & $55-60$ & $40-50$ & $55-60$ \\
\hline Sprint $(100 m)$ & $1.46(\min )$ & $\begin{array}{l}1.22 \\
(\min )\end{array}$ & $1.45(\mathrm{~min})$ & $\begin{array}{l}1.23 \\
(\mathrm{~min})\end{array}$ \\
\hline $\begin{array}{l}\text { Middle-distance } \\
\quad \text { race }(400 m)\end{array}$ & $4.56(\min )$ & $\begin{array}{l}4.62 \\
(\min )\end{array}$ & $4.32(\min )$ & $\begin{array}{l}4.46 \\
(\min )\end{array}$ \\
\hline $\begin{array}{c}\text { Long- } \\
\text { distance race }(800 \mathrm{~m} / \\
1000 \mathrm{~m})\end{array}$ & $9.79(\min )$ & $\begin{array}{l}8.60 \\
(\min )\end{array}$ & $9.84(\min )$ & $\begin{array}{l}8.45 \\
(\min )\end{array}$ \\
\hline Good-monring $(m)$ & 0.65 & 0.52 & 0.67 & 0.46 \\
\hline High jump $(m)$ & 0.94 & 1.26 & 0.89 & 1.36 \\
\hline Long jump $(m)$ & 1.39 & 1.61 & 1.40 & 1.63 \\
\hline Pull-up (1min) & 4 & 12 & 5 & 11 \\
\hline Sit-up 1(min) & 22 & 29 & 23 & 27 \\
\hline $\begin{array}{c}\text { Heart rate } \\
\text { (times/second) }\end{array}$ & 70 & 75 & 72 & 74 \\
\hline Blood pressure (Kpa) & $70-110$ & $73-114$ & $72-110$ & $76-112$ \\
\hline Vital capacity $(m l)$ & 2500 & 3200 & 2700 & 3500 \\
\hline Body fat (\%) & 34.788 & 30.535 & 36.154 & 31.151 \\
\hline
\end{tabular}

\subsection{Results analysis}

After six months of tracking and contrast testing, the students' physical changes were compared and tested, and the following test results were obtained.

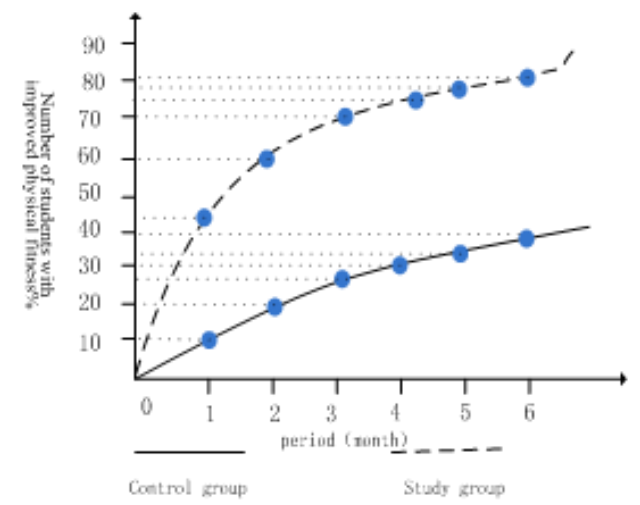

Figure 1. Compared test results of student corporeity

According to the above figure, it is not difficult to find that the students in the study group have improved their physical fitness after a large number of fancy skipping training. Compared with the 
control group, the physical quality has improved by $20 \%-45 \%$. In order to better detect the changes in the physical condition of the students, the physical indicators of the two groups of students before and after training were compared. And the following figure is given:
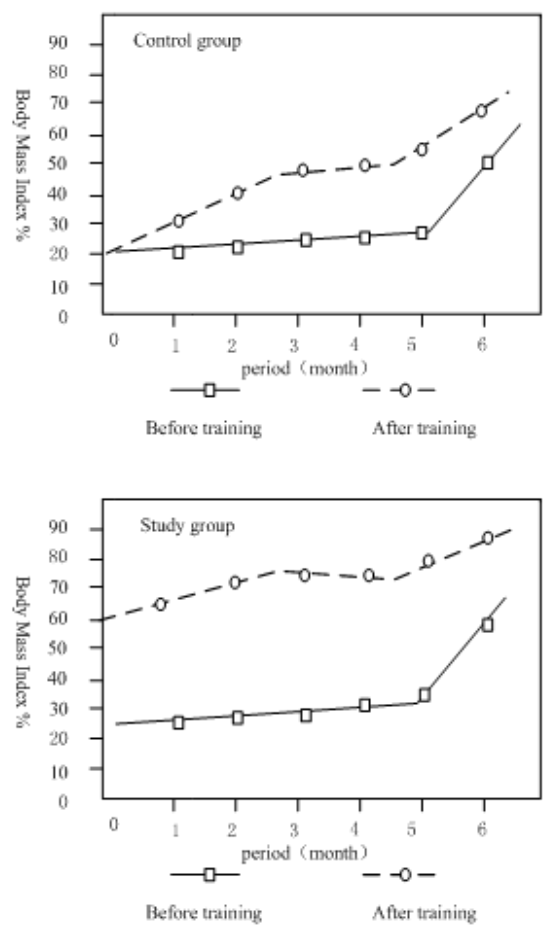

Figure 2. Detection of changes in physical fitness indexes of two groups of students before and after training

According to the above figure, it is not difficult to find that the physical condition of the two groups of students was basically the same before the test, but compared with the physical changes of the study group, the institutional improvement of the physical changes of the control group students was relatively low. It was confirmed that whether the comparison test results of the physical changes of the two groups or the results of the physical changes of the two groups of students, the improvement of the physical condition of the research group using the fancy skipping was significantly higher than that of the experimental group. It is thus confirmed that the fancy rope skipping movement has a better effect on improving the student's physical fitness.

\subsection{Results discussion}

Through long-term tracking and testing, it is found that adding pattern skipping training in the teaching process can effectively improve the student's physical condition, improve students' strength, endurance and flexibility, promote the development of limb muscles, improve students' jumping ability and explosive power. Therefore, it is recommended to incorporate the content of the skipping rope in the teaching process, to effectively improve the interest of the course, promote the healthy development of the adolescents, and cultivate students' interest in sports and athletic ability.

\section{Influence of fancy rope skipping on students' corporeity}

Through investigation and research, it is proved that the fancy ropee skipping exercise has a very favorable influence on the students' physical fitness, which can effectively promote the corporeity and physical and mental development of the students, improve the students' heart and lung function, 
exercise students' endurance and will, and promote the enhancement of students' muscle strength. By comparing the physical changes of the students in the study group, the students in the study group have significantly improved their running and jumping ability after training through the fancy skipping [8]. At the same time, the popularization of the fancy rope skipping movement combined with the driving teaching mode can effectively arouse students' interest in sports, improve students' self-confidence and happiness, and promote students' psychological and physical development. In addition, the addition of fancy rope skipping in the course education will help to better shape the student's body shape. Because the physical development of students is in an important period of growth, but due to problems such as excessive schoolwork, students are over-stressed, lack of exercise with poor health, etc. Therefore, combined with fancy teaching methods can help promote students' other changes such as height and weight.

The pattern skipping rope can effectively improve the physical function of the students. Through long-term acupuncture and aerobic training, the cardiopulmonary function of the students can be effectively improved to improve the muscle strength, body sensitivity, coordination ability and flexibility of the students, and the waist strength is significantly different. Experiments have shown that the fancy rope skipping training can improve the physical quality of primary school students in an all-round manner. It has an important influence on the healthy development of adolescents. The novelty and interest of the pattern skipping rope can effectively improve students' attention and pleasure, improve students' overall interest in sports, enhance students' self-confidence and selfexpression, relieve students' heavy work pressure, and fully stimulate students interest to participate in sports activities to learn about the fun of the fancy rope skipping.

\section{Conclusion}

It can be proved by follow-up investigation that the fancy rope skipping can effectively improve the students corporeity. Adding the fancy rope skipping to course teaching process can greatly improve students physical contidions. Therefore it's recommended to add the fancy rope skipping to course teaching content reserved to students, to cultive students interest to sport activities, stimulate students enthusiasm to sports learning, provide students with chances to participate into such matches as fancy rope skipping, effectively improve students physical fitness.

\section{Acknowledgement}

Project name: Application of driven teaching in physical education courses

Project number: JXJG-17-12-9

\section{References}

[1] CHEN An-dong, SUN Biao, ZHAO Yan. The Effects of the Undergraduates' Short Time Exercise Ability in the Way of Variable Speed Rope Skipping [J]. Journal of Nanjing Institute of Physical Education: Natural Science, 2016, 15(2):54-58.

[2] GAO Li, YANG Yong-jie, LI En-qi, FU Xian. The Effect of a Single Bout Rope Skipping Exercise on MRAN Expression of Bone Metabolism-related Factors in PBMC of Male College Students [J]. Journal of Jilin Institute of Physical Education, 2017, 33(5):32-36.

[3] CHEN Zhong, SHAN Chengxiang. Create Opportunities for Each Student to Participate in School Sports Competitions-from the Parent-Child Games and the Rope Skipping [J]. China School Physical Education, 2017,45(9):12-16.

[4] LU Zejun. Exploring the Influence of Fancy Jumping Rope on the Healthy Development of Pupils' Physical and Mental Health—Taking the Second Primary School of Luyu Town in Yuyao City as an Example [J]. Sports, 2017,47(4):124-124. 
[5] YAO Xiaojin. Feasibility Study on the Model of Jumping Rope Movement in Primary and Secondary Schools in Small Towns in Shanxi Province [J].

Contemporary Sports Technology, 2016, 6(18):77-78.

[6] ZHANG Sheng, CHEN Liang. Feasibility Analysis of Fancy Jumping Rope in Physical Education Class in Primary and Middle School__ Taking the Second Branch of The High School Affiliated to Renmin University of China as an Example [J]. Sports Time, 2016,45(24):45-56.

[7] LI Wenbao, QIU Wenxin, FENG Chuanzhi. The Influence of Motion Vision Control on Coordination-Based on Biomechanical Analysis of Skipping Action [J]. Journal of Jilin Institute of Physical Education, 2016, 32(3):41-48.

[8] LIU He-chen. High Strength of Track and Field Training and Sports Injuries Relationship Optimization Modeling and Simulation [J]. Computer Simulation, 2017, 34(3):336-339. 